\title{
Charles Taylor Against The Negative Sense Of Freedom: An Unjustified Collapse And A \\ Persisting External Authority
}

\author{
ANDREW ASKLAND \\ University of Colorado
}

\section{The Positive and the Negative Senses of Freedom}

It is not always clear what "freedom" means, in either popular parlance or academic discourse. Nor does the modifier "political" resolve the uncertainties, although it should somewhat limit their scope. 1 In an effort to elucidate some of the traditional uses of "political freedom" (or "liberty," which he considered its synonym), Isaiah Berlin differentiated between two classes of political freedom: a negative sense, which pertains to "the area within which the subject ... should be left to do or be what he is able to do or be, without interference by other persons," 2 and a positive sense, which pertains to "the source of control . . . that can determine someone to do, or be, one thing rather than another." 3 The negative sense addresses those specific things that a person can do unobstructed by others; it is "principally concerned with the area of control, not with its source." 4 The positive sense addresses the desire on the part of the individual "to be conscious of [himself] as a thinking, willing, active being, bearing responsibility for his choices and able to explain them by reference to his own ideas and purposes." 5

Whereas the negative sense takes for granted the existence of a selfaware, suitably developed person whose political freedom can be ascertained by listing the activities that are available as options (and from which activities that person chooses largely independent of social strictures or psychological limitations), the positive sense inquires into the processes that are required to produce such a self-aware, suitably developed person. The positive sense insists that, without an adequate account of this process of personal development, a list of available activities is a seriously misleading description of freedom because it ignores the individual's capacity to make appropriate use of those activities or to define herself in such a way that those activities serve as realizations of her chosen purposes.

1 The more basic question whether free will exists (or can exist) for anyone is not addressed in this paper. The implicit assumption of both Berlin and Taylor that free will can be attributed, at least conventionally, to individuals is unquestioningly accepted here as a premise.

2 Isaiah Berlin, Four Essinys on Liberly, p. 122 (Oxford University Press, 1969).

3 lbiet.

4 llid., p. 129.

5 Ibit., p. 131. 
Charles Taylor adopts the separation into negative and positive senses of freedom proposed by Berlin and adds the terms "opportunity-concept" and "exercise-concept" to flesh out his consideration of them. The "opportunity-concept" considers that "being free is a matter of what we can do, of what it is open to us to do, whether or not we do anything to exercise these options." 6 The "exercise-concept," on the other hand, considers that "one is free only to the extent that one has effectively determined oneself and the shape of one's life."7 A person is not "free, on a self-realization view, if he is totally unaware of his potential, if fulfilling it has never even arisen as a question for him, or if he is paralyzed by the fear of breaking with some norm which he has internalized but does not authentically reflect him." 8 Whereas the negative sense presumes that a more or less complete version of what one should be and want is readily apparent, the positive sense demurs that the construction of a satisfactory model of the person is a necessary condition antecedent to the exercise of freedom. The negative sense suggests that a static tabulation of available opportunities for action is a sufficient description of freedom. The positive sense insists that there is a dynamic exchange between these opportunities for action and the problematic disposition of the actor. The positive sense perceives that there is a tension between the brute availability of options and an informed awareness of their availability, i.e., whether one can articulate the option as an identifiable possibility for oneself. There is as well a tension for the actor between his meaningful choice to pursue an option in order to fulfill himself and the subsequent and persisting uncertainties about whether the option that he selected best realizes his (perhaps inchoate) capacities and aspirations.

Taylor, furthermore, is persuaded that a crude negative sense of freedom is not compatible with the intuitions of "a post-Romantic civilization which puts great value on self-realization, and values freedom largely because of this." 9 The lingering attraction of the negative sense, despite its failure to satisfy these post-Romantic intuitions, derives largely from its strategically useful simplicity: it is easier to hold "the line around a very simple and basic issue of principle, ... tough-mindedly defined as the absence of external obstacles" 10 rather than to engage in the defense of an evolving exercise-concept that is continually challengeable as to its depth or scope or legitimacy or comprehensiveness. But Taylor insists that it is the exercise-concept that comports with our intuition that freedom inevitably involves discriminations among our varying motivations. "[H]or the capacities relevant to freedom nust involve some self-awareness, self--

${ }^{6}$ Charles Taylor, The Iden of Fredom: Essays in Honour of Isiah Berlin, I:d Alan Ryan, Oxford, 1979. "What's Wrong with Negative Liburty," Reudlings: in Social and Political Philosophy, p. 177 (Oxford University l'ress, 1986).

7 Ibid.

8 lbid.

${ }^{9}$ Ibit., p. 179.

10 lbid., p. 178. 
understanding, moral discrimination and self-control, otherwise their exercise couldn't amount to freedom in the sense of self-direction." 11 The strategically useful simplicity of the opportunity-concept is fundamentally inadequate to accommodate the diversity and complexity of contemporary notions of what freedom means.

\section{The Background Conceplion}

Taylor recognizes that a crudely negative sense of freedom can be refined to address at least some of his concerns about motivation. According to the self-realization view, "you are not free if you are motivated, through fear, inauthentically internalized standards, or false consciousness, to thwart your self-realization [; . ... you have to be able to do what you really want, or to follow your real will, or to fulfill the desires of your own true self."12 Obstacles to self-fulfillment then can be both external (physical obstructions to a specific activity) and internal (mental obstructions). And these obstacles are subject to "qualitative discrimination" about their "significance," i.e., there is a "background understanding that certain goals and activities are more significant than others" 13 and a discrimination among those goals and activities "turns on . . . some sense of what is significant for human life."14 Taylor recognizes that the application of either a negative or a positive sense of freedom "requires a background conception of what is significant, according to which some restrictions are seen to be without relevance to freedom altogether, and others are judged as being of greater and lesser importance."15 It may be that the negative sense, on account of its preference for simplicity, does not accentuate or forthrightly acknowledge its relationship to such a background conception. But this relationship is nonetheless the underlying context for its evaluation of which activities are relevant to political freedom. Moreover, in so far as humans are purposeful beings, "distinctions in the significance of different kinds of freedom ... [must be] based on the distinction in the significance of different purposes." $1 \mathrm{~h}$ This background conception therefore is not reducible either to an unconscious adaptation to environmental stimuli or to an engagement with obstacles in an unreflective, seriatim order but necessarily involves judgments that support the conscious pursuit of prioritized purposes.

Taylor concedes that a negative theory can "cope" with the primary thrust of these observations, i.e., that humans make discriminations between more or less significant freedoms based upon discriminations among the purposes they have, "by simply adding a recognition that we can make

\footnotetext{
11 lliit., p. 179.

12 Ilid., p. 180

13 Ibict., p. 182.

14 Ilint., p. 183.

15 Illid.

16 llid.
} 
judgments of significance." 17 The addition clearly complicates a statement of the negative sense but, at least apparently, it does not confound it nor dilute it beyond recognition. However, when Taylor explores these judgments of significance, he concludes that the negative sense of freedom cannot provide an acceptable account of how the exercise of judgment is accomplished. In his examination of the grounds that the individual relies upon to make these qualitative discriminations, Taylor identifies the undoing of the negative sense of freedom.

Taylor considers that the positive sense of freedom, on account of its recognition of the social dimension of personhood, allows for and, in fact, mandates qualitative judgments of significance that refer to standards outside the individual person. By contrast, he considers that the negative sense of freedom is definitionally committed to the exercise of judgments of significance by the individual isolated, at least in terms of authenticating his choices, from his social setting. In Taylor's reading of the negative sense of freedom, the individual is always the "final arbiter" concerning what constitutes a "true, authentic desire or purpose."18 The individual is "the final authority as to what his freedom consists in, and cannot be second-guessed by external authority." 19

\section{Strong Evaluation}

Taylor justifies these observations about the inadequacy of the negative sense (due to the absence of an external authority) with "the fact of strong evaluation." 20 Because I can identify desires which, though they motivate me, are not merely comparatively bad but are absolutely bad, then 1 must conclude that when such desires do in fact motivate me, they detract from my freedom. These absolutely bad desires "are all things which I can easily see myself losing without any loss whatsoever to who I am. This is why I can see them as obstacles to my purposes, and hence to my freedom, even though they are in a sense unquestionably desires and feelings of mine." 21

This strong evaluation, which acknowledges that "human subjects are not only subjects of first-order desires, but of second-order desires, desires about desires,"22 makes explicit the challenge of internal obstacles to the negative sense of freedom. The person who does what he wants, when that means pursuing certain first-order desires which he recognizes are absolutely bad, is nonetheless acting freely according to the cructe negative sense of freedom. But that person is not acting freely, on account of the kind of desires that motivate the action, according to the positive sense of

17 Ibid., p. 184
18 lbid., p. 186.
19 lbid., p. 187
20 lbid., p. 185.
21 lbid., p. 186.
22 Ibid., p. 184. 
freedom. Doing what I want to do, as a standard applied independent of an account of motivation that ranks competing desires in order to sanction some acts as expressive of freedom and to condemn others as subversive of freedom, does not comport with the fact of strong evaluation. "We have to make discriminations among motivations and accept that acting out of some motivations . . . is not freedom, is even a negation of freectom." 23

Additionally, if we are aware of desires that do not promote our freedom, we should also allow for the possibility that there are desires which we believe promote our freedom but which in fact do not. Because we appreciate that some of the desires that motivate us are positively bad, "[h]ow can we exclude in principle that there may be other false appreciations which the agent does not detect?" 24 There are persuasive grounds then, according to Taylor, to avoid defining freedom as action unless that definition makes satisfactory reference to both the ranking of motivations for the action and the prospects for a false appreciation of that ranking. But when a negative sense of freedom attempts to accommodate these considerations, it is pulled from the simplicity of a listing of available activities to an account that is both complicated and tentative. It is complicated because it must qualify its list of activities with the proviso that conditions those activities as expressions of freedom only if their performances are properly motivated. It is tentative because the list of activities is attended by the further proviso that it is not always possible to determine whether a seemingly proper motivation is actually what it seems. A commitment to a negative sense of freedom needs to incorporate an account of motivations that satisfies both of these provisos if it is to coexist with contemporary notions of freedom as an enlightened self-fulfillment. But the radical reorientation necessitated by these proposed modifications raises the question whether the negative sense can survive the modifications other than as a cumbersome relic of a largely preempted structure.

Taylor emphatically denies that the negative sense of freedom can be reconstructed to accommodate the challenge of strong evaluation. The proposal to admit judgments of significance offered an initially plausible strategy but it ultimately proves unable to reconcile a ranking of motivations (that freedom as self-realization requires) with the negative sense's insistence that the individual is the final authority about his desires or purposes. The hybrid that would result from incorporating a compelling account of motivations within the negative sense is deemed "untenable." The core commitment of the negative sense to the individual as the arbiter of what he authentically wants precludes second-guessing of his choices by an external authority. Thus the privileged position of the individual and his antagonism against second-guessing is said to "rule out in principle that the subject can ever be wrong obout what he wants." 25 But, as Taylor eagerly points out,

23 Ibiit., p. 186.

24 Iliit., p. 191.

25 Iliit., p. 187. 
"how can he never, in principle, be wrong, unless there is nothing to be right or wrong about in this matter?"26 Given that there clearly are things about which one can be wrong, viz., at the least, undetected but absolutely bad desires, the incompetence of the negative sense of freedom to address personal error and thus its incompatibility with contemporary expectations about freedom as self-realization are apparent.

\section{The Collapse of the Political into the Personnl}

The first criticism of Taylor's analysis is that it is not always clear where the boundaries of political freedom lie vis $a$ vis freedom in general and personal freedom in particular. He purports to accept the differentiation proposed by Berlin, but his development of the contrasting theories of political freedom quickly loses track of their political orientation. His extensive treatment of the psychology of personal development and the importance of authentic self-expression suggests that all political freedoms must be viewed through the lens of continuous individual self-analysis. The right to vote, for example, might seem a simple political freedom. Or, at least, its complexities would seem to pertain to the effectiveness of the vote cast, describable in terms of fraudulent tabulation procedures or the dearth of viable candidates or some related method of assessment that addresses tangible qualities of the value of the franchise. But, pursuant to Taylor's analysis, we need to address issues of self-realization when we evaluate this right to vote. Presumably, we need to undertake an unbounded study of the innumerable possibilities for self-deception when we evaluate that right, e.g., does the overwhelming number of voters produce a personal sense of futility, or does the low percentage participation of eligible voters contribute to a sense of anomie and disaffection, or does participation in the process serve to defuse an otherwise accumulating conviction that the democratic process is ineffectual, etc., ad infinitum. Pursuant to Taylor's approach, there can never be a fixed and firm political freedom. A certain equilibrium does not seem inconsistent with his view but it is ever prey to destabilizing influences that are borne of an individual's failure to grasp the true significance of the freedom involved. Inasmuch as political freedoms are significant only to the extent that they serve personal self-realization, their relative merits will rise and fall as they are exercised by properly motivated individuals, whenever and however we can decide who those individuals are.

It does seem to be the case that political freedom is related to personal freedom. From this insight into the impotently nominal nature of a political freedom where someone cannot take advantage of that freedom for reasions of irrational fear (or some other, absolutely bad, internal obstacle), Taylor wrests a comprehensive damning of political freedom unless it means self-expression. But acknowledging that there is a relationship between

20 lbid. 
political freedom and personal freedom does not justify the collapse of the former into the latter. When a distinction is maintained between them, every problem for personal freedom is not a problem to the same degree and in the same manner for political freedom.

Surely grave threats to personal freedom have serious ramifications for political freedom as well, but those ramifications need to be drawn out explicitly against those freedoms that are properly political. Subtle hindrances to self-expression, e.g., borne of parental influence or religious training, are certainly relevant to the realization of personal freedom but those subtle hindrances may be, at best, tangentially related to a sense of self as politically free. Short of those situations where such hindrances effect a significant and perceptible diminution of that sense of self as politically free, one might conclude that problems of personal freedom are largely irrelevant to political freedom. And those instances where a significant and perceptible impact is detected would justify efforts to either relieve the hindrance or modify the political freedom to account for the hindrance.

At the furthest extreme, a reconciliation of personal freedom with political freedom may be impossible because of a glaring deficiency in a particular individual's conception of one sense of freedom or the other. A negative theory of political freedom need only prefatorily disqualify severely disturbed persons in order to address the extreme cases, e.g., Charles Manson and Andreas Baader, and it has provided at least a plausible (if largely conventional and self-referential) response to the problem of absolutely bad motivations. This disqualification procedure hardly suffices to reconcile Taylor's ideas about self-realization with a negative sense of political freedom. But it does acknowledge that a seriously distorted conception of personal freedom is incompatible with political freedom and therefore adopts a minimal test of personal competency to address the problem of the seriously distorted political player.

The obvious retort to this simple disqualification procedure is that it is not only in the seriously distorted exceptions but also in the routine and common instances where an account of personal freedom must underlie an account of political freedom. But the insistence upon such a link can be accommodated if the two kinds of freedom are consistently distinguished from one another. Indeed, a negative theory of political freedom may seem vulnerable to Taylorish criticisms about absolutely bad motivations because implicitly it already does distinguish between personal and political freedom. As a theory of political freedom, it presupposes a separate account of personal freedom that addresses instances of absolutely bad motivations. That supposition is not part of the negative theory per se and sol when the negative theory, stripped of the supposition, is criticized for failing to satisfactorily address motivations, it does not have a practiced and reacty rebuttal.

But this apparent failure is not fatal if it can be unpacked as the inadequacy of a negative sense stripped of its motivational presumptions rather than the inadequacy of that negative sense supported by those 
presumptions. Undoubtedly the motivational presumptions of a negative sense of freedom will prove to be considerably less rich than the typology of motivations developed by Taylor for a positive sense of freedom (and they may be ultimately unpersuasive to a theorist committed to the positive sense on account of this comparative sparseness). Yet these motivational presumptions likely do address, even if at a perfunctory or superficial level, problems like absolutely bad motivations. The reason why they are not specifically articulated in a negative sense of freedom is that they are not deemed properly part of a political theory. Instead, they are considered to be part of the theory of personal freedom which underlies and supports that theory of political freedom. For the negative sense, theories of political freedom are distinguished from theories of personal freedom, at least by implication. Inasmuch as they are related but distinguishable, it is not surprising that a brief (and unsympathetic) summary of negative political theory will not recognize its implicit dependence upon a theory of personal freedom. A critique of negative political theory that ignores this relationship, especially when that critique insists upon a rich account of personal freedom, is likely to misstate the entailments of a negative political theory for personal freedom in order to trumpet the more auspicious circumstances for personal freedom that lie in a positive theory of political freedom.

\section{The Persistence of External Authority}

Aside from this concern for the unconstrained collapsing of political freedom into personal freedom, there is another shortcoming present to Taylor's analysis of negative freedom. While the temptation to collapse the political into the personal is not unique to Taylor (but instead applies to various accounts of the positive sense of freedom), this second concern is especially applicable to Taylor. He judges that the negative sense of freedom is inadequate to explain absolutely bad motivations (especially when undetected) because it is necessarily committed to the individual as the final arbiter of her desires and purposes. The individual, so restricted, has no assured means of discovering the shortcomings of her desires and purposes. No matter how erroneous they may be, i.e., the fruit of undetected and absolutely bad motivations, until the individual on her own initiative recognizes the shortcomings, she is entitled to and, incleed, must act as her desires move her. There is allegedly no motivational hierarchy available that acknowledges an external authority according to which those desires are deficient. But it is not clear that the negative sense is committed to this position that the individual is an uninformed but nevertheless irrefutable. final arbiter. A bare statement of the negative sense perhaps can be read (1) imply that the individual is an isolated arbiter, but that implication does not fit within a fuller account that explicitly identifies an authority to distinguish goud from bad motivations, to the degree that they become manifest in actions, that is external to the individual. 
It is fairly clear that the negative sense of freedom largely ignores concerns about self-realization and false consciousness. To that extent it neglects the plight of the individual who cannot take proper advantage of an externally unobstructed activity because there are debilitating motivational obstacles. It is a less rich and appealing account of political freedom on account of that neglect, especially in those instances where political and personal freedom are closely intertwined. The freedom of speech, for example, is complicated in the example where specific tokens of speech may be inimical to both the speaker and the party addressed because of the undeveloped (as an example, racist) condition of the speaker. It is a fair criticism of the negative sense of freedom that it primarily focuses upon the freedom of speech (and its instances) as a freedom exercised by the speaker without adequately acknowledging the potential for its abuse of a freedom of the listener.

Despite this prevailing deficiency in apologies for the negative sense of freedom, no necessary connection exists between that negative sense and an unqualified endorsement of the individual as the final arbiter of their desires and purposes. Presumably because the negative sense of freedom does not address instances of potential abuse, it can therefore be read to sanction such abuses as irreproachably neutral "opportunities" to do something that it is open for one to do. But the simplicity of the negative sense does not constitute an endorsement of such abuses. The negative sense does not offer a persuasive rejoinder to these instances of abuse because it does not anticipate motivational complications or because it presumes that an underlying theory of personal freedom will resolve the potential for abuse before it arises as an expression of political freedom. In either case, there are grounds to criticize the negative sense of political freedom for its awkward response to instances of abusive political expression. But in neither case need the individual be isolated from an external authority as an unavoidable entailment of the negative sense of freedom.

The freedom of speech example is again useful to demonstrate the decisiveness and the flexibility of external sources that determine which activities are protected as political freedoms. The first statement of the political freedom as a right to freely express one's point of view seems direct and unequivocal. But when the reach of that definition is curtailed in order to exclude fighting words used in certain highly volatile situations or declarations of false danger that entail grave risk of public harm or false assertions that seriously debase another's professional or personal reputation, the negative sense of freedom can and does accommodate such curtailments. The explanation may be that these objectionable instances do not qualify as speech-acts or, allowing that they are speech-acts, that they are trumped by other, weightier considerations (derived from other political freedoms). Moreover, the limits of these exceptions are not dependent upon an interpretation by each individual as an isolated and final arbiter. There are communal standards that govern defamation, for example, and individual decisions about what to say about whom are evaluated in light of 
these external standards. A negative sense of freedom is not hapless when challenged with proposed limitations upon a specific freedom nor when persuaded of the evolving character of those limitations as functions of societal norms.

A negative theory of freedom may not suitably address the reasons why a particular speech act is unhealthy for the specific speaker, given her idiosyncratic motivations. But it can and does address the speech act itself and it relies upon an authority external to the speaker to make its evaluation. Indeed, Taylor's criticism of the negative sense of freedom on the grounds that there is an absence of external authority seems misguided. It is true that the negative sense attempts little evaluation of the uniquely persional motivations that spur individual actions and, to that extent, overlooks psychologically penetrating accounts of human behavior. Instead, the negative sense evaluates the actions themselves according to their ordinary and usual meanings, i.e., according to standards external to the individual. The individual's motivations are generally neglected in favor of a description of the actions performed.27 The political freedoms that are protected are fairly simply described as types of action free from interference and their sweep is as wide as is conventionally appropriate to them. Indeed, there is a pervasive air of conventionality and mutual accommodation in these descriptions that belie Taylor's suggestion that an unbridled egoism lurks within the negative sense.

Rather than ignoring external authority, the negative sense of freedom seems vulnerable to criticism for too heavily relying upon such external authority in its evaluation of what counts as political freedom. The individual's motivations to exercise these freedoms, to the extent that they are unaddressed, may not comport with a preferred background conception. And so the individual may be allowed to exercise those freedoms for the wrong reasons. But the exercise is monitored and directed according to an external authority which will interfere when those reasons spill over and are expressed in excess of the protections allowed. Bad motivations as such are not addressed by the negative sense of freedom, but their expressions in action are. The individual cannot effectively serve as the final arbiter of her motivations whenever those motivations manifest themselves as actions because the actions will be evaluated by an external authority. That authority will forcibly interfere and, by interfering, provoke her to reassess her motivations. The negative sense of freedom then does provide an external authority that encourages a reassessment of a motivation's shortcomings when that motivation finds expression in conduct that is adjudged unacceptable. Although the individual may be left to form (or reform) desires and purposes independent of external authority, that individual is certainly not the final arbiter whether the expression of those desires and purposes qualifies as a political freedom.

27Motivations are perhaps considered to the extent that they clarify otherwise ambiguous actions. 